CARDIOVASCULAR MEDICINE

\title{
New support for clarifying the relation between ST segment resolution and microvascular function: degree of ST segment resolution correlates with the pressure derived collateral flow index
}

\author{
M Sezer, Y Nisanci, B Umman, E Yilmaz, A Olcay, F Erzengin, O Ozsaruhan
}

Heart 2004;90:146-150. doi: 10.1136/hrt.2002.009985

See end of article for authors' affiliations

.....................

Correspondence to: Dr Murat Sezer, Istanbul Universitesi, Istanbul Tip Fakultesi, Kardiyoloji Anabilim Dalı Capa, Istanbul, Turkey; msezer@superonline.com

Accepted 29 May 2003

\begin{abstract}
Objective: To investigate the relation between the degree of ST segment resolution (STR) after thrombolysis and the pressure derived collateral flow index (CFlp), determined using an intracoronary pressure measurement technique in patients with recent myocardial infarction.

Methods: 33 patients were studied. TIMI grade III flow was achieved in the infarct related artery by thrombolysis. A surface ECG was obtained on admission and 90 minutes later. The sum of ST segment elevations was measured by summing all leads with ST elevation on the baseline ECG and on the 90 minute ECG (after thrombolysis) and calculating the percentage recovery. The study population was divided into two groups, with good STR ( $\geqslant 50 \%$; group 1) or poor STR $(<50 \%$; group 2 ). After angiography, a fibreoptic pressure monitoring guidewire was advanced to the stenosis to be dilated. The CFlp was determined as the ratio [coronary wedge pressure - central venous pressure]/[mean aortic pressure - central venous pressure].

Results: The mean STR on the surface ECG was $54.6 \%$ and mean (SD) CFlp was 0.25 (0.12) (range 0.10 0.41 ). There was an inverse correlation between the individually calculated percentage of STR and CFIp $(r=-0.64, \mathrm{p}<0.01)$. The mean CFlp was lower in patients with a good STR than in those with a poor STR (0.18 (0.07) v $0.27(0.10), p<0.02)$.

Conclusions: Although TIMI grade III flow was achieved after thrombolysis, a worse STR on the surface ECG was associated with higher CFlp measured in the infarct related artery. CFlp appears to reflect the degree of microvascular obstruction by quantifying impedance of the microvasculature.
\end{abstract}

R esolution of ST segment elevation has been shown to be a simple and useful predictor of final infarct size, left ventricular function, and clinical outcome after both thrombolytic and interventional approaches to the management of acute myocardial infarction. ${ }^{1-3}$ It is known that a patent epicardial artery does not necessarily result in reperfusion at a cellular level, and it has been suggested that ST segment recovery may be a better marker of myocyte reperfusion. ${ }^{4-6}$ Determination of a pressure derived collateral flow index (CFIp), assessed by intracoronary pressure measurement with a pressure monitoring guidewire, makes it possible to evaluate collateral function in the non-infarcted heart. ${ }^{7}$ However, after acute myocardial infarction, CFIp is significantly influenced by the severity of the dysfunction in the ischaemic microvasculature. ${ }^{9}$

Our objective in this study was to evaluate the correlation between the degree of ST segment resolution (STR) and CFIp in patients with acute myocardial infarction treated with thrombolysis, in whom TIMI (thrombolysis in myocardial infarction) grade III flow was achieved in the infarct related artery after thrombolysis.

\section{METHODS}

\section{Study patients}

We studied 33 patients between September 1999 and August 2001. They all presented within six hours of symptom onset (typical chest pain lasting more than 30 minutes) with ST segment elevation in at least two contiguous leads. They were treated with tissue plasminogen activator. The angiographic inclusion criteria were as follows:
- TIMI grade III flow in the infarct related artery
- single vessel disease
- all destined for stent implantation.

\section{ECG evaluation}

Standard 12 lead ECGs were obtained at baseline and at 90 minutes after admission. All ECGs were evaluated by a single investigator blinded to the angiographic data. The ST segment was measured $20 \mathrm{~ms}$ after the $\mathrm{J}$ point. The summed ST segment elevation was measured by summing the ST amplitude in all leads with ST elevation at baseline (before fibrinolysis) and at 90 minutes (postfibrinolysis), using methods described previously by Schröder and colleagues. ${ }^{10}$ The per cent resolution of STR was calculated as the initial sum of ST segment elevation minus the sum of ST segment elevation on the second ECG, divided by the initial sum of ST segment elevation. STR was also categorised on a dichotomous scheme which defined it as good $(\geqslant 50 \%)$ or poor $(<50 \%) .{ }^{11}{ }^{12}$

\footnotetext{
Abbreviations: CFIp, pressure derived collateral flow index; CWP, coronary wedge pressure; FFRmyo, myocardial fractional flow reserve; STR, ST segment resolution; TIMI, thrombolysis in myocardial infarction; $\mathrm{Pa}$, proximal aortic pressure; $\mathrm{Pd}$, distal aortic pressure; $\mathrm{Pv}$, central venous pressure
} 


\section{Angiographic analysis and intracoronary pressure measurements}

Cardiac catheterisation was done at a mean of four days after the myocardial infarct. Left and right coronary angiography and left ventriculography were achieved in all patients. TIMI flow grades were assessed as previously described. ${ }^{13}$ Angiographic collateral grade was determined by two observers using Rentrop's classification. ${ }^{14}$ After angiography, a fibreoptic pressure monitoring guide wire (pressure wire, 0.014 inch $(0.36 \mathrm{~mm})$, Radi Medical Systems, Sweden) was set at zero, calibrated, advanced through the guiding catheter, and positioned distal to the stenosis to be dilated. The same wire was used as a guidewire for the angioplasty catheter. Proximal aortic (Pa), distal aortic (Pd), and central venous $(\mathrm{Pv})$ pressures were recorded simultaneously. Adenosine was used as the hyperaemic agent, given in intracoronary bolus doses of $20 \mu \mathrm{g}$ for the left coronary system and $15 \mu \mathrm{g}$ for the right coronary system, and repeated if necessary. Myocardial fractional flow reserve (FFRmyo) was calculated under adenosine hyperaemia as the ratio of mean Pd minus Pv to mean Pa minus Pv. During the stent implantation procedure, when total occlusion was achieved by balloon occlusion, the distal pressure obtained from the pressure wire was recorded as the coronary wedge pressure (CWP, mm Hg). CFIp (unitless) was calculated as the ratio of simultaneously measured CWP minus Pv to mean Pa minus Pv.

\section{Statistical analysis}

Statistical analysis was done using SPSS 10.0 for Windows. Data are expressed as mean (SD). A probability value of $\mathrm{p}<0.05$ was considered significant. Differences between groups were evaluated by $\chi^{2}$ analysis for categorical variables and by Student's $t$ test for continuous variables. The Pearson correlation analysis was used to investigate relations between variables.

\section{RESULTS}

The baseline clinical and angiographic characteristics of the patients are given in table 1. Most of the patients presented with anterior wall infarction, and the left anterior descending coronary artery was the culprit vessel in $66 \%$ of the patients. All the patients had TIMI grade III flow in the infarct related artery on coronary angiography, which was done at a mean of four days after the myocardial infarct.

\section{ST segment resolution}

The mean (SD) ST segment resolution was $54(26) \%$. The study population was divided into two groups according to whether they had good STR ( $\geqslant 50 \%$; group 1) or poor STR $(<50 \%$; group 2). Poor STR was observed in 11 of the 33 patients. There were no differences between the two groups with respect to angiographic or clinical characteristics. Preinfarction angina tended to be more frequent in patients with good STR (27\% v 45\%) (table 1).

\section{Intracoronary pressure measurement}

Basal and hyperaemic mean Pa and Pd before and after stent implantation were not different between the two groups. Mean FFRmyo values before and after stent implantation were also similar (table 2). However, mean CWP (18.2 (9.5) $v$ 28.2 (10.1) mm Hg, p<0.02) and CFIp (0.18 (0.07) v 0.27 $(0.10), p<0.02)$ were significantly lower in patients with good STR than in those with poor STR (figs 1 and 2).

There were also significant inverse correlations between CWP and STR $(r=-0.69, \mathrm{p}<0.01)$ (fig 3) and CFIp and STR $(r=-0.64, \mathrm{p}<0.01)$ (fig 4$)$, implying that higher CFIp and CWP are associated with poorer STR.

\section{Angiographic collateral grade and CFIp and STR}

There was no difference in CFIp among the patients with collateral grades 0 to 3 (grade 0: $0.20(0.09)$; grade 1: 0.25 (0.12); grade 2: 0.22 (0.11); grade 3: 0.25 (0.08); NS). There was also no relation between CFIp and collateral grade $(r=0.16)$ (fig 5).

We found no differences between the two groups with respect to angiographic collateral grades $(p=0.41)$.

\section{DISCUSSION}

To our knowledge, this study represents the first investigation of the correlation between the extent of ST segment resolution and the degree of microvascular destruction determined by intracoronary pressure measurement in patients with reperfused acute myocardial infarction. We found that a greater STR was associated with lower CFIp values.

Table 1 Baseline angiographic and clinical characteristics

\begin{tabular}{|c|c|c|c|c|}
\hline & $\begin{array}{l}\text { All patients } \\
(n=33)\end{array}$ & Good STR (n=22) & Poor STR $(n=11)$ & p Value \\
\hline \multicolumn{5}{|l|}{ Clinical characteristics } \\
\hline Age (years) & $58.2(11.2)$ & $59.3(10.4)$ & $56.4(9.5)$ & NS \\
\hline Male/female & $23 / 10$ & $16 / 6$ & $7 / 4$ & NS \\
\hline Diabetes mellitus & $9(27 \%)$ & $6(27 \%)$ & $3(27 \%)$ & NS \\
\hline Hypertension & $13(39 \%)$ & $8(36 \%)$ & $5(45 \%)$ & NS \\
\hline Smoking & $20(60 \%)$ & $14(63 \%)$ & $6(54 \%)$ & NS \\
\hline Dyslipidaemia & 11 (33\%) & $7(31 \%)$ & $4(36 \%)$ & NS \\
\hline History of angina & $11(33 \%)$ & $6(27 \%)$ & $5(45 \%)$ & NS \\
\hline $\begin{array}{l}\text { Time from symptom onset to } \\
\text { treatment (hours) }\end{array}$ & $4.7(1.1)$ & $4.3(1.2)$ & $4.9(1.4)$ & NS \\
\hline Days from $\mathrm{AMI}$ to $\mathrm{PCl}$ & $5.0(1.1)$ & $4.7(1.5)$ & $5.2(1.7)$ & NS \\
\hline \multicolumn{5}{|l|}{ Angiographic characteristics } \\
\hline LAD & $22(66 \%)$ & $14(63 \%)$ & $8(72 \%)$ & NS \\
\hline RCA & $4(13 \%)$ & $2(9 \%)$ & $2(18 \%)$ & NS \\
\hline CxA & $7(21 \%)$ & $4(18 \%)$ & $3(27 \%)$ & NS \\
\hline Baseline diameter stenosis (\%) & $64.2(11.6)$ & $63.8(14.4)$ & $65.5(13.4)$ & NS \\
\hline Collateral grade $0 / 1 / 2 / 3$ & & $50 \% / 32 \% / 16 \% / 2 \%$ & $55 \% / 36 \% / 11 \% / 0 \%$ & NS \\
\hline \multicolumn{5}{|c|}{$\begin{array}{l}\text { Values are } \mathrm{n}(\%) \text { or mean }(\mathrm{SD}) \text {. } \\
\mathrm{AMI} \text {, acute myocardial infarction; CxA, circumflex coronary artery; LAD, left anterior descending coronary artery, } \\
\mathrm{PCl} \text {, percutaneous coronary intervention; RCA, right coronary artery; STR, ST segment resolution (good, } \geqslant 50 \% \text {; } \\
\text { poor, }<50 \%) \text {. }\end{array}$} \\
\hline
\end{tabular}


Table 2 Intracoronary pressure measurements

\begin{tabular}{|c|c|c|c|c|}
\hline & $\begin{array}{l}\text { All patients } \\
(n=33)\end{array}$ & $\begin{array}{l}\text { Good STR } \\
(\mathrm{n}=22)\end{array}$ & $\begin{array}{l}\text { Poor STR } \\
(n=11)\end{array}$ & p Value \\
\hline $\mathrm{Pa}$, pre-stent, basal $(\mathrm{mm} \mathrm{Hg})$ & $85.3(10.1)$ & $82.2(9.4)$ & $86.4(10.1)$ & NS \\
\hline $\mathrm{Pa}$, pre-stent, hyperaemic $(\mathrm{mm} \mathrm{Hg})$ & $87.3(10.4)$ & $88.9(11.5)$ & $86.4(9.5)$ & NS \\
\hline $\mathrm{Pa}$, post-stent, basal (mm Hg) & $88.3(9.2)$ & $87.8(9.8)$ & $89.6(10.6)$ & NS \\
\hline $\mathrm{Pa}$, post-stent, hyperaemic $(\mathrm{mm} \mathrm{Hg})$ & $89.4(8.8)$ & $90.1(10.1)$ & $88.2(11.2)$ & NS \\
\hline $\mathrm{Pd}$, pre-stent, basal (mm Hg) & $69.4(8.5)$ & $67.3(9.4)$ & $70.2(10.4)$ & NS \\
\hline $\mathrm{Pd}$, pre-stent, hyperaemic $(\mathrm{mm} \mathrm{Hg})$ & $53.5(9.2)$ & $51.2(10.2)$ & $53.4(9.8)$ & NS \\
\hline $\mathrm{Pd}$, post-stent, basal (mm Hg) & $84.3(8.0)$ & $83.2(9.2)$ & $81.2(10.2)$ & NS \\
\hline $\mathrm{Pd}$, post-stent, hyperaemic $(\mathrm{mm} \mathrm{Hg})$ & $83.2(8.8)$ & $80.4(9.3)$ & $84.8(10.1)$ & NS \\
\hline FFRmyo, pre-stent & $0.60(0.10)$ & $0.58(0.09)$ & $0.61(0.11)$ & NS \\
\hline FFRmyo, post-stent & $0.92(0.12)$ & $0.91(0.11)$ & $0.92(0.12)$ & NS \\
\hline $\operatorname{Pv}(\mathrm{mm} \mathrm{Hg})$ & $6(2)$ & $8(3)$ & $7(3)$ & NS \\
\hline CWP (mm Hg) & $27.2(11.3)$ & $18.2(9.5)$ & $28.2(10.1)$ & $<0.02$ \\
\hline CFlp & $0.25(0.12)$ & $0.18(0.07)$ & $0.27(0.10)$ & $<0.02$ \\
\hline \multicolumn{5}{|c|}{$\begin{array}{l}\text { Values are mean (SD). } \\
\text { CWP, coronary wedge pressure; CFIp, pressure derived collateral flow index; FFRmyo, myocardial fractional flow } \\
\text { reserve; Pa, proximal aortic pressure; } \mathrm{Pd} \text {, distal aortic pressure; } \mathrm{Pv} \text {, central venous pressure; STR, ST segment } \\
\text { resolution (good, } \geqslant 50 \% \text {; poor, }<50 \% \text { ). }\end{array}$} \\
\hline
\end{tabular}

\section{ST segment resolution as a marker of myocardial tissue perfusion}

The primary goal of reperfusion therapy has shifted from opening of the infarct related artery to establishment of myocardial tissue perfusion. ${ }^{15}{ }^{16}$ It has been reported that STR is a practical and useful measure of this latter variable. ${ }^{11} 1217$ Several studies have shown that persistent ST elevation is predictive of poor recovery of left ventricular function and of increased mortality, even among patients with TIMI grade 3 flow after a percutaneous coronary intervention. ${ }^{18}{ }^{19}$ This finding is supported by results from contrast echocardiography, ${ }^{20}$ nuclear scintigraphy, ${ }^{21}$ and Doppler flow wire studies, ${ }^{22}$ which show that no reflow in the microvasculature is associated with poor recovery of left ventricular function, even when patency has been restored in the infarct related artery. Santoro and colleagues demonstrated a relation between failure of ST resolution and reduced myocardial perfusion assessed by contrast echocardiography. ${ }^{23}$ In another study it was confirmed that early resolution of ST segment elevation correlated with myocardial salvage as assessed by Tc-99m sestamibi scintigraphy. ${ }^{24}$ It has been shown that patients with $\geqslant 50 \%$ STR have improved left ventricular function and reduced mortality. ${ }^{25}{ }^{26}$ In the present study, 33\% of the patients had poor STR $(<50 \%)$ after thrombolysis, implying that extensive tissue and microvascular injury had occurred in a substantial number of the patients, although all

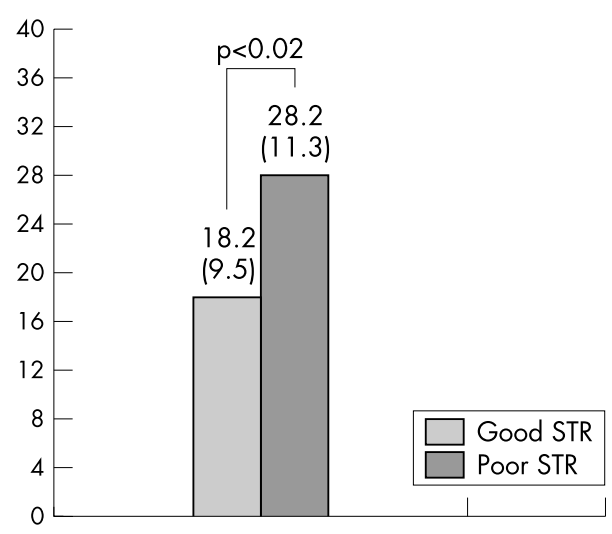

Figure 1 Mean coronary wedge pressure (CWP, $\mathrm{mm} \mathrm{Hg}$ ) values in patients with good ( $\geqslant 50 \%)$ and poor $(<50 \%)$ ST segment resolution (STR). had TIMI grade 3 flow at the coronary angiography. The pressure derived collateral flow index was found to be raised in this group of patients. We also found that there was a significant inverse correlation between CFIp and STR, implying that a higher CFIp is associated with poorer STR. This finding suggests that CFIp is affected by microvascular dysfunction even in reperfused patients with TIMI grade 3 flow after acute myocardial infarction, and that it reflects the degree of microvascular dysfunction.

\section{Pressure derived collateral flow index as a marker of microvascular obstruction}

Several studies have reported that intracoronary pressure measurements with a pressure wire permit the assessment of collateral function in the non-infarcted heart. ${ }^{27-29}$ The CFIp is hypothesised to increase with an increase in collateral flow. However, in the infarcted heart CFIp is not associated with well developed collateral channels. Yamamuto and colleagues showed that the CFIp does not necessarily reflect collateral function in patients with acute myocardial infarction. ${ }^{9}$ They observed that the CFIp is influenced by the presence and severity of ischaemic microvascular dysfunction in acute myocardial infarction, and that a higher CFIp is associated with the no reflow phenomenon and with worse functional outcomes. The relation we found between STR and CFIp (a higher CFIp is associated with a poorer STR) is similar to that

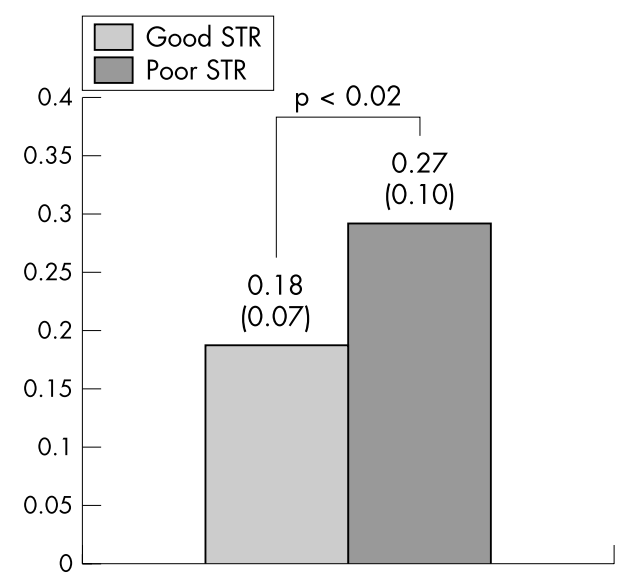

Figure 2 Mean pressure derived collateral flow index (CFlp) in patients with good and poor STR. 


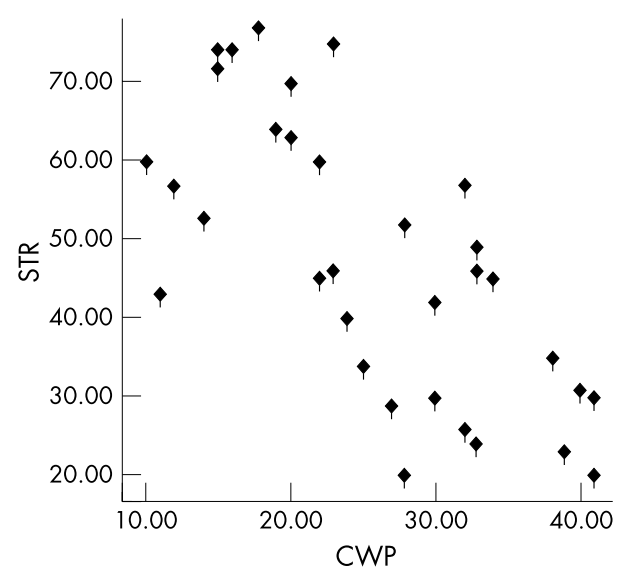

Figure 3 Relation between coronary wedge pressure (CWP) and ST segment resolution (STR). There was significant correlation between two variables $(r=-0.69, \mathrm{p}<0.01)$.

observed by Yamamuto and colleagues, ${ }^{9}$ who used myocardial contrast echocardiography as a marker of tissue perfusion. In the normal heart, coronary blood flow fills the intramyocardial blood pool and partially runs through the coronary microvasculature into the venous circulation. Extensive microvascular obstruction in the infarcted region can cause congestion of the intramyocardial blood pool. Because of this obstruction, intramyocardial blood pressure should increase with an increase in myocardial wall stress. Thus an increase in mean CWP and CFIp in patients with reperfused infarct related arteries but poor STR on the surface ECG (group 2) is probably related to a greater degree of obstruction in the microvasculature, and these variables can be taken as a marker of the impedance of the distal microvasculature. The inverse correlations found between mean CFIp and STR suggest that a higher CFIp is associated with further destruction in the microcirculation. We did not find any relation between the degree of angiographic collateralisation and CFIp. Thus these variables do not necessarily reflect collateral function in the presence of microvascular dysfunction, which may occur even in patients with acute myocardial infarction and TIMI grade 3 flow. In this study we also showed that although TIMI grade 3 flow was restored after thrombolysis, a sizeable proportion of the patients $(33 \%)$ probably had abnormal perfusion at the cellular level, as evidenced by a poor STR on the surface ECG. This finding is supported by our measurements of CFIp, a marker of microvascular dysfunction.

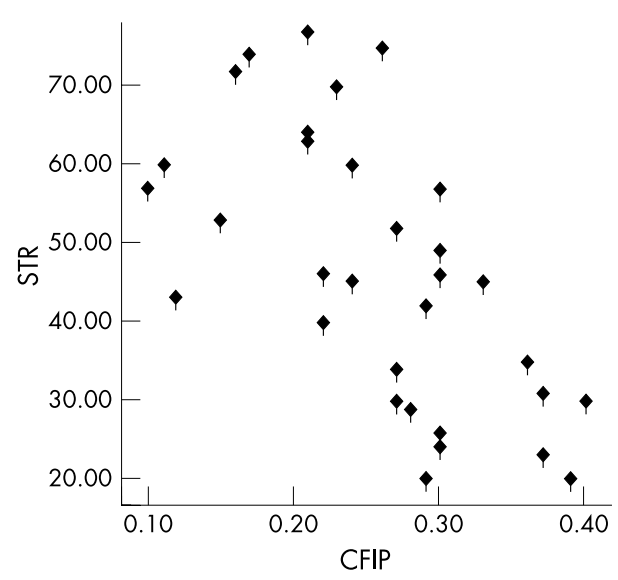

Figure 4 There was significant inverse correlation between STR and the pressure derived collateral flow index (CFlp) $(r=-0.64, \mathrm{p}<0.01)$.

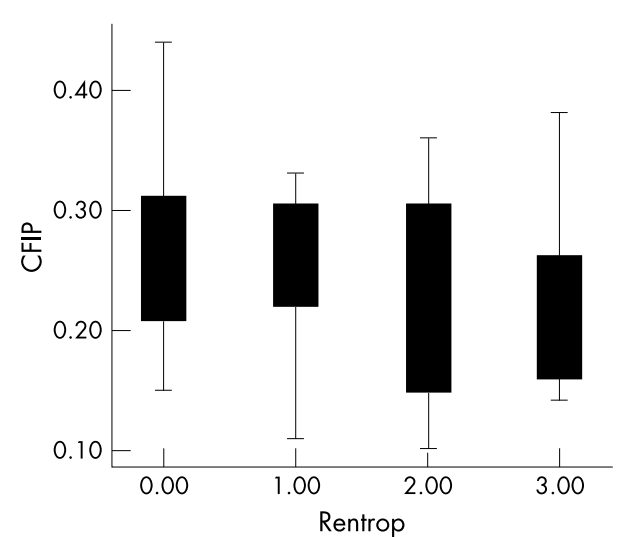

Figure 5 Comparison of pressure derived collateral flow index among angiographic collateral grades. There was no correlation between these two variables $(r=0.16)$.

\section{Study limitations}

Our findings were derived from a selected population of patients with acute myocardial infarction who were treated with thrombolysis and in whom TIMI grade III flow was restored in the infarct related artery. Thus our results cannot be generalised to all patients receiving reperfusion therapy. Second, our study population was relatively small and a larger number of patients may be necessary to confirm our results.

\section{Conclusions}

The results support the hypothesis that ST resolution is a surrogate marker of tissue level reperfusion. This study provides further clarification of the relation between STR after thrombolysis and microvascular function, using the CFIp as another measure of microvascular dysfunction.

\section{ACKNOWLEDGEMENTS}

Part of this study was presented as an oral contribution at the 75th AHA Scientific Congress, Chicago, USA, and was published in abstract form in Circulation (2002;106:NN-1-II-992, II-597, 2949).

\section{Authors' affiliations}

M Sezer, Y Nisanci, B Umman, E Yilmaz, A Olcay, F Erzengin,

O Ozsaruhan, Istanbul University, Istanbul Faculty of Medicine, Department of Cardiology, Istanbul, Turkey

\section{REFERENCES}

1 Pepine CJ. Prognostic markers in thrombolytic therapy: looking beyond mortality. Am J Cardiol 1996;78:24-7.

2 de Lemos JA, Braunwald E. ST segment resolution as a tool for assessing the efficacy of reperfusion therapy. J Am Coll Cardiol 2001;38:1283-94.

3 Angeja BG, Murphy AS, et al. TIMI myocardial perfusion grade and ST segment resolution: association with infarct size as assessed by single photon emission computed tomography imaging. Circulation 2002; 105:282

4 Taniyama Y, Higashino Y, Fujii K, et al. Myocardial perfusion patterns related to thrombolysis in myocardial infarction perfusion grades after angioplasty in patients with acute anterior wall myocardial infarction. Circulation 1996:93:1993-9.

5 Porter RT, Shouping L, Oster R, et al. The clinical implications of no reflow demonstrated with intravenous perfluorocarbon containing microbubbles following restoration of thrombolysis in myocardial infarction (TIMI) 3 flow in patients with acute myocardial infarction. Am J Cardiol 1998;82:1173-7.

6 van't Hof AWJ, Liem A, de Boer M-J, et al. Clinical value of 12-lead electrocardiogram after successful reperfusion therapy for acute myocardial infarction. Lancet 1997;350:615-19.

7 Pijls NHJ, Bech JW, El Gamal HJH, et al. Quantification of recruitable coronary collateral blood flow in conscious human and its potential to predict future ischemic events. J Am Coll Cardiol 1995;25:1552-8.

8 Seiler C, Fleish M, Garachemani A, et al. Coronary collateral quantitation in patients with coronary artery disease using intravascular flow velocity or pressure measurements. J Am Coll Cardiol 1998;32:1272-9. 
9 Yamamuto K, lto $\mathrm{H}$, Iwakura $\mathrm{K}$, et al. Pressure-derived collateral flow index as a parameter of microvascular dysfunction in acute myocardial infarction. J Am Coll Cardiol 2001;38:1383-9.

10 Schröder R, Wegscheider K, Schroder K, et al. Extend of early ST segment elevation resolution: a strong prediction of outcome in patients with acute myocardial infarction and a sensitive measure to compare thrombolytic regimen. A substudy of the international joint efficacy comparison of thrombolysis (INJECT) trial. J Am Coll Cardiol 1995;26:1657-64.

11 Somitsu Y, Nakamura M, Degawa T, et al. Prognostic value of slow resolution of ST-segment elevation following successful direct percutaneous translumina coronary angioplasty for recovery of left ventricular function. Am J Cardiol 1997;80:406-10.

12 Matezky S, Novikov M, Gruberg L, et al. The significance of persistent ST elevation versus early resolution of ST segment elevation after primary PTCA J Am Coll Cardiol 1999:34:1932-8.

13 Chescbro JH, Knattend G, Robert R, et al. Thrombolysis in myocardial infarction (TIMI) trial, phase I: a comparison between intravenous plasminogen activator and intravenous streptokinase. Circulation 1987:76:142-54.

14 Rentrop KP, Cohen M, Blanke $H$, et al. Changes in collateral channel filling immediately after controlled coronary artery occlusion by angioplasty balloon in human subjects. J Am Coll Cardiol 1985;5:587-92.

15 Roe MT, Ohman EM, Maas ACP, et al. Shifting the open artery hypothesis downstream: the quest for optimal reperfusion. J Am Coll Cardiol $2001 ; 37: 9-18$

16 Rezkalla SH, Kloner RA. No reflow phenomenon. Circulation 2002; 105:656-62.

17 Matetzky S, Freimark D, Chouraqui P, et al. The distinction between coronary and myocardial reperfusion after thrombolytic therapy by clinical markers of reperfusion. J Am Coll Cardiol 1998;32:1326-30.

18 Somitsu Y, Nakamura M, Degawa T, et al. Prognostic value of slow resolution of ST-segment elevation following successful direct percutaneous transluminal coronary angioplasty for recovery of left ventricular function. Am J Cardiol 1997;80:406-10.

19 Santoro G, Antoniucci D, Valenti R, et al. Rapid resolution of ST-segment elevation after successful direct angioplasty in acute myocardial infarction. Am J Cardiol 1997;80:685-9.
20 Ito $\mathrm{H}$, Tomooka T, Sakai $\mathrm{N}$, et al. Lack of myocardial reperfusion immediately after successful thrombolysis: a predictor of poor recovery of left ventricular function in anterior myocardial infarction. Circulation 1992;85:1699-705.

21 Kondo $M$, Nakano $A$, Saito $D$, et al Assessment of microvascular no-reflow phenomenon using technetium- $99 \mathrm{~m}$ macro-aggregated albumin scintigraphy in patients with acute myocardial infarction. Circulation 1998;32:898-903.

22 Neumann FJ, Blasini R, Schmitt C, et al. Effect of glycoprotein Ilb/IIIA receptor blockade on recovery of coronary flow and left ventricular function after placement of coronary artery stents in acute myocardial infarction. Circulation 1998;98:2695-701.

23 Santoro GM, Valenti R, Buonamici $P$, et al. Relation between ST-segment changes and myocardial contrast echocardiography in patients with acute myocardial infarction treated with direct angioplasty. Am J Cardiol 1998;82:932-7.

24 Early resolution of ST-segment elevation correlates with myocardial salvage assessed by Tc-99m sestamibi scintigraphy in patients with acute myocardial infarction after mechanical or thrombolytic reperfusion therapy. Circulation 2002; 105:2946-9.

25 Purcell IF, Newall N, Farrer M. Change in ST segment elevation 60 minutes after thrombolytic initiation predicts clinical outcome as accurately as later electrocardiographic changes. Heart 1997;78:465-71

26 de Lemos JA, Antman EM, Giugliano RP, et al. Comparison of a 60- versus 90-minute determination of ST-segment resolution after thrombolytic therapy for acute myocardial infarction. Am J Cardiol 2000;86:1235-7.

27 Pijls NH, van Son JA, Kirkeeide RL, et al. Experimental basis of determining maximum coronary, myocardial and collateral blood flow by pressure measurements for assessing functional stenosis severity before and after percutaneous transluminal coronary angioplasty. Circulation 1993;87:1354-67

28 Seiler C, Fleish M, Garachemani A, et al. Coronary collateral quantitation in patients with coronary artery disease using intravascular flow velocity or pressure measurements. J Am Coll Cardiol 1998;32:1272-9.

29 Pijls NHJ, Bech JW, El Gamal HJH, et al. Quantification of recruitable coronary collateral blood flow in conscious human and its potential to predict future ischemic events. J Am Coll Cardiol 1995;25:1552-8.

\section{IMAGES IN CARDIOLOGY}

\section{Combined membrane covered and uncovered stents for coronary arteriovenous fistula associated with atherosclerotic plaque in a patient with acute myocardial infarction}

S tent grafts have recently been applied for various coronary lesions such as coronary perforation, coronary aneurysm, and fistula. We report a case of coronary arteriovenous fistula associated with atherosclerotic plaque successfully treated with combined membrane covered and uncovered stent implantation in a patient who presented with acute myocardial infarction. He was found to have acute ST segment elevation myocardial infarction. A 12 lead ECG showed ST segment elevation of $3 \mathrm{~mm}$ over the precordial leads (VlV5). Cardiac enzymes were elevated and peaked at $1161 \mathrm{iu} / \mathrm{l}$ of creatine kinase (CK), $130 \mathrm{iu} / \mathrm{l}$ of CK-MB, $0.804 \mathrm{ng} / \mathrm{ml}$ of troponin $\mathrm{T}$, and $7.98 \mathrm{ng} / \mathrm{ml}$ of troponin I. Two dimensional echocardiogram demonstrated severe hypokinesia in anteroseptal and anterior wall. A coronary angiogram revealed critical stenosis in the proximal left anterior descending coronary artery and prestenotic dilatation with a large fistula drained into the main pulmonary artery
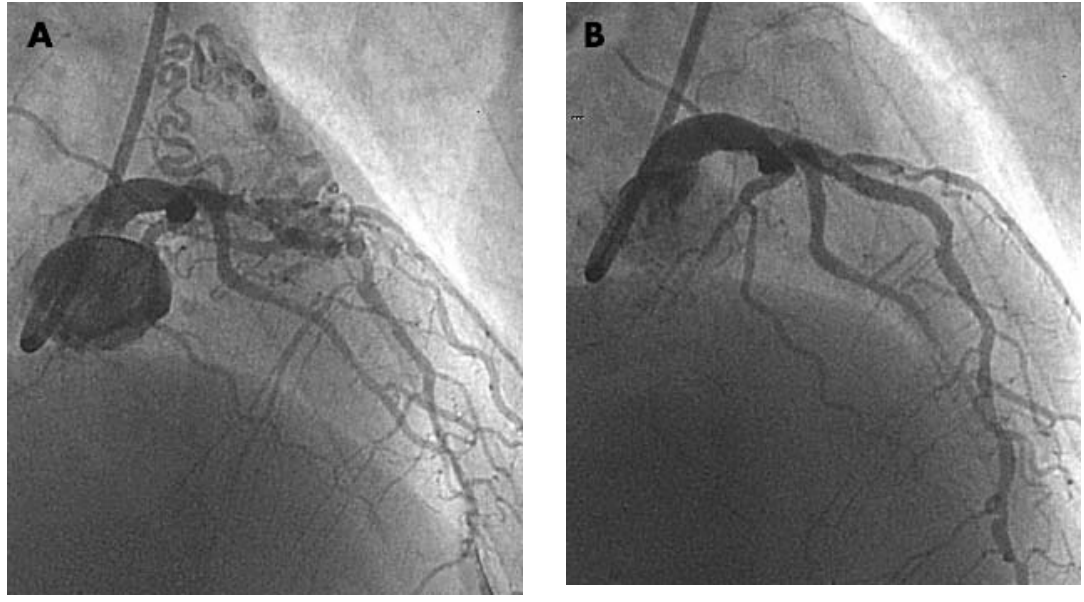

(panel A). After predilation in fistula and stenosis sites, a polytetrafluoroethylene (PTFE) covered stent $(3.0 \times 16 \mathrm{~mm}$, JOSTENT GraftMaster, Jomed, Germany) was deployed. After graft stenting, an additional uncovered stent $(3.0 \times 18 \mathrm{~mm}$, Arthos inert, AMG, Korea) was implanted just below the graft stented site. After stenting, no visible large fistula and stenosis were found on angiography (panel B).

Y Ahn

O Y Park

$\mathrm{MH}$ Heong cecilyk@hanmail.net 